\title{
Information sharing and lending market competition under strong adverse selection
}

\author{
Jorge Fernández-Ruiz • Miguel García-Cestona
}

Received: 6 March 2012 / Accepted: 7 July 2012 / Published online: 4 August 2012

(C) The Author(s) 2012. This article is published with open access at SpringerLink.com

\begin{abstract}
In a relatively recent paper, Gehrig and Stenbacka (Eur Econ Rev 51, 77$99,2007)$ show that information sharing increases banks' profits to the detriment of creditworthy entrepreneurs in a model of a banking duopoly with switching costs and poaching. They restrict their analysis to the case in which adverse selection is not too strong. We analyze the complementary case and show that, when the economy suffers from strong adverse selection, information sharing still increases banks' profits, but it may or may not hurt talented entrepreneurs.
\end{abstract}

Keywords Information sharing · Lending relationships · Poaching · Equilibrium switching

JEL Classification $\quad \mathrm{G} 21 \cdot \mathrm{L} 15 \cdot \mathrm{D} 82$

\section{Introduction}

In a relatively recent paper, Gehrig and Stenbacka (2007) (henceforth G\&S) show that the sharing of information in credit markets increases banks' equilibrium profits at the expense of talented entrepreneurs in a duopoly with switching costs and poaching.

\footnotetext{
J. Fernández-Ruiz

El Colegio de México, Camino al Ajusco 20. Pedregal de Sta.

Teresa, 01000 México, DF, México

e-mail: jfernan@colmex.mx

M. García-Cestona $(\varangle)$

Depart. d'Economia de l'Empresa, Fac. Econòmiques,

Universitat Autònoma de Barcelona,

Edifici B, 08193 Bellaterra, Barcelona, Spain

e-mail: Miguel.Garcia.Cestona@uab.es
} 
G\&S restrict their attention to the case in which adverse selection is not too strong, meaning that the proportion of talented entrepreneurs is sufficiently large.

In this paper we extend their analysis to the complementary case of strong adverse selection. We find that information sharing continues to lead to higher banks' profits-for the same reasons that G\&S explain—but it may hurt or benefit talented entrepreneurs.

In both G\&S and the current paper, information sharing has the potential to increase welfare because the information provided by a rival bank about its customers allows a bank to reduce the costs that arise when the bank tries to attract its rival's customers. In particular, a bank can reduce the financing costs from providing capital (in the second period) to projects known by its rival to be unproductive. Moreover, when the information provided by a rival leads a bank to change the offers that it makes to this rival's customers, the set of consumers that switch banks and the resulting overall switching costs may also change.

In their analysis of the mild adverse selection case, G\&S find that information sharing allows a bank to refrain from lending to its rival's untalented customers, but that the gains from not financing these unproductive projects are invalidated by softer competition in the first period: information sharing induces the banking profits to increase by more than the cost savings in lending, because information sharing also relaxes price competition in period 1. Thus, information sharing also adds a strategic component to bank profits, which ultimately represents a transfer from talented entrepreneurs to banks (Gehrig and Stenbacka 2007, p. 90).

Here we find that in the complementary situation of strong adverse selection (i.e., of a low proportion of creditworthy entrepreneurs) there are two distinct cases to consider with respect to the potential welfare-enhancing effects of information sharing.

1. When the proportion of talented entrepreneurs is very low (the meaning of "very low" will become clear below), in the absence of information sharing a bank does not make any offer to its rival's customers (there is no poaching) and, therefore, there is no financing of projects of unknown quality. Since there are neither unproductive projects being financed nor customers switching banks, the potential gains from information sharing disappear. By relaxing competition in the initial period, information sharing increases banks' profits to the detriment of talented entrepreneurs.

2. When the proportion of talented entrepreneurs is moderately low, in the absence of information sharing banks make some poaching offers and finance some unproductive projects (there is randomized poaching). In this case, the sharing of information reduces the financing costs resulting from providing capital to unproductive projects as well as switching costs. We find that the size of these gains may or may not outweigh the increase in banks' profits due to the softening of competition in the first period and, therefore, the final outcome is that information sharing may hurt or benefit talented entrepreneurs.

The rest of our exposition is organized as follows. Section 2 briefly describes the model. Section 3 derives the equilibrium when there is no information sharing. Section 4 deals with the changes that occur when banks agree to share information, by comparing the 
equilibrium under information sharing derived in G\&S with the equilibrium in Sect. 3. Finally, Sect. 5 concludes.

\section{The model}

The model in G\&S can be described as follows. There are two periods, $t=1$ and 2 , two banks, A and B, and two types of entrepreneurs (or borrowers), talented and untalented. In each period, entrepreneurs have access to projects that require borrowing from banks one unit of capital, with opportunity cost $R_{0}$. Talented entrepreneurs undertake projects that yield a positive return, $v$, with probability $\pi$ and zero otherwise, while untalented entrepreneurs' projects always yield zero. It is common knowledge that a proportion $\lambda$ of entrepreneurs are talented. At the beginning of period one, banks compete for borrowers of unknown type by setting one-period (gross) interest rates $R_{1}^{i}, \mathrm{i}=\mathrm{A}, \mathrm{B}$. Upon observing these interest rates, borrowers choose one bank. After this, investments are carried out, returns are obtained, repayments are made, and banks learn the types of their own customers. Since entrepreneurs are protected by limited liability, they default - and repay nothing to the banks — when realized returns are zero which occurs when, either the entrepreneur is untalented or the project of a talented entrepreneur becomes unsuccessful.

In period two, competition between banks can take place under two different information structures, with and without information sharing. In the first case, both banks will know all the borrowers' types. In contrast, in the absence of information sharing, each bank will know its borrowers' types but it will not know the types of its rival's borrowers. In either case, a bank's willingness to make a loan to a particular borrower, as well as the interest rate on such a loan, may depend on this borrower's previous history. A bank will (not) make an offer to an entrepreneur if the bank has learned that this entrepreneur is (un)talented, and it may or may not make an offer to a rival's unknown first-period customer. If bank $i$ offers to make a loan to a customer in period two, the (gross) interest rate on this loan will be $R_{2}^{i}$ if this customer is bank $i$ 's previous borrower and $Q_{2}^{i}$ if it is not. Borrowers choose again one of the banks. If they choose to switch banks, they will incur an idiosyncratic switching cost b, which is drawn from a uniform distribution on the interval $[0, \bar{b}]$. Borrowers privately learn the realization of $b$ at the beginning of the second period, before making their choice. Finally, second-period investments are carried out, returns are obtained and repayments are made. We derive now the equilibria in the different set-ups.

\section{Equilibrium without information sharing}

\subsection{Equilibrium in period 2}

In their paper, $G \& S$ consider a situation with a high proportion of talented entrepreneurs $\left(\lambda \geq 9 R_{0} /\left(9 R_{0}+\bar{b}\right)\right)$. They show that in such a case it is a symmetric equilibrium that each bank $i(\mathrm{i}=\mathrm{A}, \mathrm{B})$ offers a rate $R_{2}^{i}=\left(2 \bar{b}+3 R_{0}\right) / 3 \pi$ to its own talented customers and a poaching rate $Q_{2}^{i}=\left(\bar{b}+3 R_{0}\right) / 3 \pi$ to its rival's customers. 
G\&S implicitly assume that these equilibrium rates are no higher than the return $v$, which is equivalent to assuming $2 \bar{b} \leq 3\left(\pi v-R_{0}\right)$ : the net present value of the project of a talented entrepreneur is large in relation to switching costs. The equilibrium rates imply that the poaching profits for bank $i$ on bank $j$ 's customers are:

$$
\left(1-\mu_{i}\right)\left(\lambda \bar{b} / 9-(1-\lambda) R_{0}\right)
$$

where $\mu_{i}$ is bank $i$ 's first-period market share. These poaching profits will be negative if the proportion of talented entrepreneurs is small, which corresponds to the following condition:

$$
\lambda<R_{0} /\left(R_{0}+\bar{b} / 9\right)
$$

G\&S focus their attention on the case in which the condition (2) does not hold and, therefore, the poaching profits in (1) are positive. In contrast, we concentrate on the complementary situation where condition (2) is satisfied. We say that there is strong adverse selection if this condition holds. In such a situation, we can distinguish two different cases. In the first case, there is a symmetric equilibrium where each bank $i$ refrains from making poaching offers to its rival bank's customers and-expecting no poaching offers from the rival bank-offers rates as high as possible $\left(R_{2}^{i}=v\right)$ to its own talented customers. In the second case, these strategies are not equilibrium strategies. ${ }^{1}$ The reason is that even though, given that the rival bank $j$ does not make any poaching offer, the rate $R_{2}^{i}=v$ maximizes bank $i$ 's profits on its own customers, $\mu_{i} \lambda\left(\pi R_{2}^{i}-R_{0}\right)$, bank $i$ is able to obtain positive poaching profits on its rival's first-period costumers when the rival sets $R_{2}^{j}=v$. In this second case, there is no symmetric equilibrium in pure strategies in which banks do not offer any poaching rate and we have to rely on mixed-strategy equilibria. We look for an equilibrium in which each bank $i$ offers the rate $R_{2}^{i}$ to its own customers and randomizes between making a poaching offer $Q_{2}^{i}$ to the rival bank's customers and refraining from making any poaching offer at all. To ensure the existence of equilibrium whenever there is strong adverse selection, either in pure or mixed strategies, we restrict attention to the case $(9 / 8)\left(\pi v-R_{0}\right) \leq 2 \bar{b}$. Since we keep the assumption $2 \bar{b} \leq 3\left(\pi v-R_{0}\right)$ implicit in $\mathrm{G} \& \mathrm{~S}$, we assume that

$$
(9 / 8)\left(\pi v-R_{0}\right) \leq 2 \bar{b} \leq 3\left(\pi v-R_{0}\right)
$$

In the following proposition we characterize the second-period equilibrium.

Proposition 3.1 (Equilibrium in period 2) Assume that there is no information sharing, condition (3) holds, and there is strong adverse selection $\left(\lambda<R_{0} /\left(R_{0}+\bar{b} / 9\right)\right)$. Let $\lambda^{*}=4 \bar{b} R_{0} /\left(4 \bar{b} R_{0}+\left(\pi v-R_{0}\right)^{2}\right)$.

(a) If $\lambda<\lambda^{*}$, bank $i(i=A, B)$ will make no offer to the rival bank's first-period customers, and an offer $R_{2}^{i}=v$ to its own talented customers, leading to second-period profits $G_{2}^{i}=\mu_{i} \lambda\left(\pi v-R_{0}\right)$.

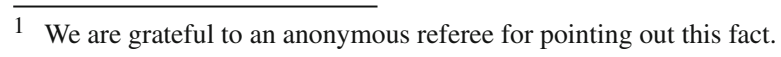


(b) If $\lambda^{*}<\lambda<R_{0} /\left(R_{0}+\bar{b} / 9\right)$, bank $i(i=A, B)$ will make an offer $R_{2}^{i}=$ $\left(3 \alpha R_{0}+2 \bar{b}\right) /(3 \alpha \pi)$ to its own talented customers, and it will make an offer $Q_{2}^{i}=\left(3 \alpha R_{0}+\bar{b}\right) /(3 \alpha \pi)$ to the rival bank's first-period customers with probability $\alpha$, and no offer with probability $(1-\alpha)$, being $\alpha=\left(\lambda \bar{b} / 9(1-\lambda) R_{0}\right)^{1 / 2}$. All this leads to second-period equilibrium profits, $G_{2}^{i}=\mu_{i} \lambda(4 \bar{b} / 9 \alpha)$.

Proof See Appendix.

Remark $\lambda^{*}<R_{0} /\left(R_{0}+\bar{b} / 9\right)$ if and only if $2 \bar{b}<3\left(\pi v-R_{0}\right)$.

It is worth emphasizing that banks obtain no profits from poaching their rival's customers because, either they refrain from making poaching offers at all or they make such offers with probability $\alpha<1$. Thus, they are indifferent between making these offers and refraining from doing so.

\subsection{Equilibrium in period 1}

Bank $i^{\prime} s$ inter-temporal discounted profits are $G^{i}=G_{1}^{i}+\delta G_{2}^{i}$, where $\delta$ denotes the common discount factor and $G_{1}^{i}$ the first-period profits, which are given by:

$$
G_{1}^{i}=\mu_{i}\left[\lambda \pi R_{1}^{i}-R_{0}\right]
$$

The combination of strong adverse selection and no information sharing creates a protected second-period market, where each bank obtains high profits on their initial customers and is unable to obtain any profits by poaching its rival's previous customers. The following proposition tells us that the anticipation of this second-period configuration leads banks to such an intense competition to attract customers in the first-period that banks' overall profits vanish.

Proposition 3.2 (Equilibrium in period 1) Assume that condition (3) holds, there is strong adverse selection $\left(\lambda<R_{0} /\left(R_{0}+\bar{b} / 9\right)\right)$ and no information sharing. Then, bank $i(i=A, B)$ obtains overall profits $G^{i}=0$ and sets $(a) R_{1}^{i}=\left[R_{0}-\delta \lambda\left(\pi v-R_{0}\right)\right] / \lambda \pi$ if $\lambda<\lambda^{*}$ and (b) $R_{1}^{i}=\left[R_{0}-\delta \lambda(4 \bar{b} / 9 \alpha)\right] / \lambda \pi$ if $\lambda>\lambda^{*}$.

Proof See Appendix.

It is also important for future reference to calculate the talented entrepreneurs' expected sum of debt repayments and switching costs, TC:

$$
\begin{array}{cl}
\mathrm{TC}=R_{0}[(1 / \lambda)] & \text { if } \lambda<\lambda^{*} \\
R_{0}[(1 / \lambda)+\delta+\delta \alpha(1-\lambda) / \lambda]+\delta \bar{b} / 18 \alpha & \text { if } \lambda>\lambda^{*}
\end{array}
$$

If $\lambda<\lambda^{*}$ firms never switch banks, which implies that they do not incur in any switching costs and TC consists solely in debt repayments, $T C=\pi R_{1}^{i}+\delta \pi R_{2}^{i}$, which results in Eq. (5) after replacing $R_{1}^{i}$ in Proposition 3.2 and $R_{2}^{i}$ in Proposition 3.1. In this case, $\mathrm{TC}$ is equal to the repayments that reach a break-even point, taking 
into account that the banks finance untalented entrepreneurs in the first period but not in the second one.

If $\lambda>\lambda^{*}$, firms receive an offer to switch banks with probability $\alpha$ and, therefore, $T C=\pi R_{1}^{i}+\delta \alpha E \min \left[\pi R_{2}^{i}, \pi Q_{2}^{j}+b\right]+\delta(1-\alpha) \pi R_{2}^{i}$.

Now, since $E \min \left[\pi R_{2}^{i}, Q_{2}^{j}+b\right]=\int_{0}^{\pi\left(R_{2}^{i}-Q_{2}^{j}\right)}\left[\pi Q_{2}^{j}+b\right](1 / \bar{b}) d b+\int_{\pi\left(R_{2}^{i}-Q_{2}^{j}\right)}^{\bar{b}}$ $\pi R_{2}^{i}(1 / \bar{b}) d b$, we obtain TC as expressed in Eq. (5), using $R_{2}^{i}$ and $Q_{2}^{i}$ as in Proposition 3.1, and $R_{1}^{i}$ as in Proposition 3.2.

In this scenario, the repayments that allow banks to break even are represented by $R_{0}[(1 / \lambda)+\delta+\delta \alpha(1-\lambda) / \lambda]$, where the third term inside the brackets captures the fact that untalented entrepreneurs receive financing in the second period with probability $\alpha$. This financing is inefficient and it constitutes an adverse selection cost that raises the repayments that talented entrepreneurs need to make for banks to break even. Furthermore, the term $\delta \bar{b} / 18 \alpha\left(=\int_{0}^{\pi\left(R_{2}^{i}-Q_{2}^{j}\right)} b(1 / \bar{b}) d b\right)$ captures the switching costs incurred by talented entrepreneurs.

\section{The consequences of information sharing}

\subsection{Equilibrium under information sharing}

Under information sharing, poaching occurs no matter how strong the problem of adverse selection is. This is so because both banks know all entrepreneurs' types and are able to lend only to talented ones. G\&S show that the second-period equilibrium interest rates are:

$$
\hat{R}_{2}^{i}=\left(2 \bar{b}+3 R_{0}\right) / 3 \pi, \quad \hat{Q}_{2}^{i}=\left(\bar{b}+3 R_{0}\right) / 3 \pi, \quad(i=A, B)
$$

regardless of the value of $\lambda$ [Proposition 4.1 in Gehrig and Stenbacka (2007)]. These rates imply that a bank's second-period poaching profits will be $\left(1-\mu_{i}\right)(\lambda \bar{b} / 9)$. G\&S also show that, for any $\lambda$, the first-period equilibrium interest rates become:

$$
\hat{R}_{1}^{i}=\left(R_{0}-\delta \lambda \bar{b} / 3\right) / \lambda \pi
$$

and that each bank $i$ 's overall equilibrium profits are:

$$
\hat{G}^{i}=\delta(\lambda \bar{b} / 9)>0
$$

Since $G^{i}=0$ (Proposition 3.2 above), information sharing increases banks' profitsjust as it happens in G\&S. In the absence of information sharing a bank can obtain second-period profits only from its first-period borrowers, and these profits are competed away in the first-period. In contrast, under information sharing a bank can obtain second-period profits on its rival's customers. The poaching profits that a bank can obtain, regardless of its first-period customers, constitute "reservation" profits that are not eliminated in first-period competition. 
The sum of expected repayments and switching costs for talented entrepreneurs under information sharing

$$
\hat{T} C=\pi \hat{R}_{1}^{i}+\delta E \min \left[\pi \hat{R}_{2}^{i}, \pi \hat{Q}_{2}^{j}+b\right]
$$

can be expressed now [after using $\hat{R}_{2}^{i}$ and $\hat{Q}_{2}^{i}$ in (6) and $\hat{R}_{1}^{i}$ in (7)] as follows:

$$
\hat{T} C=R_{0}[(1 / \lambda)+\delta]+2 \delta \bar{b} / 9+\delta \bar{b} / 18
$$

The first of the three terms of $\hat{T} C$ captures the repayments that talented entrepreneurs have to make for banks to break even. The second term measures the repayments they make for banks to obtain the profits expressed in Eq. (8). And, finally, the last term captures the talented entrepreneurs' expected switching costs, $\delta \int_{0}^{\pi\left(\hat{R}_{2}^{i}-\hat{Q}_{2}^{j}\right)} b(1 / \bar{b}) d b$ $=\delta \bar{b} / 18$.

To see whether information sharing decreases the lifetime utility of talented entrepreneurs, we only need to see if it increases their overall debt repayments and switching expenditures-by comparing TC in (5) with $\hat{T} C$ in (10). These entrepreneurs receive financing regardless of the information sharing regime.

When $\lambda<\lambda^{*}$,

$$
\hat{T} C-T C=2 \delta \bar{b} / 9+\delta \bar{b} / 18>0
$$

and, therefore, information sharing hurts talented entrepreneurs. There are two reasons for this to happen, which correspond to the two terms in the RHS in (11). First, information sharing increases the talented entrepreneurs' repayments by $2 \delta \bar{b} / 9$ to raise banks' profits. Second, it also increases switching costs (by $\delta \bar{b} / 18$ ) because banks do not make poaching offers to rival banks' customers in the absence of information sharing, but they do make such offers when information is shared.

When $\lambda>\lambda^{*}$,

$$
\hat{T} C-T C=2 \delta \bar{b} / 9+\left(-\delta \alpha(1-\lambda) R_{0} / \lambda\right)+\delta \bar{b}(\alpha-1) / 18 \alpha
$$

The RHS Eq. (12) captures the three effects that information sharing has on talented entrepreneurs' expenditures. The first term is positive and indicates that it increases their repayments, so that banks' profits become larger. The second term is negative, and captures the savings in adverse selection costs that information sharing achieves by allowing banks to detect untalented entrepreneurs and refrain from lending them. The third term is also negative and represents the savings that information sharing causes in switching costs, despite the fact that it does not alter the proportion of talented entrepreneurs that switch banks, which remains equal to (1/3). Information sharing achieves these savings because it changes the set of entrepreneurs that switch banks in a way that their average switching costs are reduced. To see this, notice that, without information sharing, talented entrepreneurs receive a poaching offer with probability $\alpha$ and, in such a case, they switch banks if they have a switching cost below the cut-off 
value of $\pi\left(R_{2}^{i}-Q_{2}^{j}\right)=\bar{b} / 3 \alpha$. In contrast, with information sharing, talented entrepreneurs always receive a poaching offer. But only those entrepreneurs with switching costs below the lower cut-off value $\pi\left(\hat{R}_{2}^{i}-\hat{Q}_{2}^{j}\right)=\bar{b} / 3$ will switch banks. The net effect of the three terms in $(\hat{T} C-T C)$ in (12) may be either positive or negative, as simple calculations (using the fact that $\delta \bar{b} / 9 \alpha=\delta \alpha(1-\lambda) R_{0} / \lambda$ ) show:

$(\hat{T} C-T C)>0$ if and only $\lambda>\left[81 R_{0} /\left(81 R_{0}+25 \bar{b}\right)\right] \equiv \lambda^{* *}$.

The following proposition summarizes these results.

Proposition 4.1 (Equilibrium in period 1) Assume that condition (3) holds and there is strong adverse selection $\left(\lambda<R_{0} /\left(R_{0}+\bar{b} / 9\right)\right)$. Then:

(a) If $\lambda<\lambda^{*}$, information sharing will increase each bank's overall profits (by $\delta(\lambda \bar{b} / 9))$, as well as the expected switching costs incurred by talented entrepreneurs (by $\delta(\bar{b} / 18)$ ), without altering adverse selection costs-which remain equal to zero. As a result, information sharing reduces the life-time utility of talented entrepreneurs.

(b) If $\lambda>\lambda^{*}$ information sharing will not only increase each bank's overall profits (by $\delta(\lambda \bar{b} / 9)$ ), but it will also reduce adverse selection costs $\left(\right.$ by $\left.\delta \alpha(1-\lambda) R_{0}\right)$ and the expected switching costs incurred by talented borrowers $($ by $\delta \bar{b}(1-\alpha) \lambda / 18 \alpha)$. As a result, information sharing will decrease the life-time utility of talented entrepreneurs if $\lambda>\lambda^{* *}$ and will increase it if $\lambda^{*}<\lambda<\lambda^{* *}$.

Remark $\lambda^{*}<\lambda^{* *}$ if and only if $2 \bar{b}<(9 / 5)\left(\pi v-R_{0}\right)$. In such a situation, information sharing may or may not hurt talented entrepreneurs. Otherwise, $\lambda^{* *} \leq \lambda^{*}$, and information sharing will always hurt them.

\section{Conclusion}

In this paper we have examined whether the main result in G\&S, the existence of a conflict of interest between banks and creditworthy entrepreneurs with respect to information sharing, continues to hold when the economy suffers from strong adverse selection.

The answer to this question can be presented in two parts. First, we have shown that the G\&S result that information sharing increases banks' profits, as well as the intuition for why it holds, extends to the case of strong adverse selection. In this complementary situation, a bank has such an informational disadvantage over the characteristics of its rival's customers that it cannot obtain positive profits from them in the absence of information sharing. Thus, a bank obtains profits only on its previous customers. In a two-period model, first-period competition takes into account such future profits and eliminates overall rents. In contrast, when there is information sharing, banks are able to obtain profits from poaching their rival's customers in the second period. Importantly, banks can obtain poaching profits even if they do not attract consumers in the first period. These second-period profits turn out to be "inescapable rents" that are not competed away in the first period.

Second, with respect to the potential welfare enhancing gains from information sharing, we have shown that there are two distinct cases to be considered. When the 
proportion of talented entrepreneurs is very low (i.e., $\lambda<\lambda^{*}$ ), banks completely refrain from making poaching offers to their rival's customers in the absence of information sharing. As a result, there are neither unproductive projects being financed, nor costs from switching banks and, therefore, no gains to be obtained from information sharing. The increase in banks' profits harms talented entrepreneurs. In the other scenario the proportion of talented entrepreneurs is moderately low (i.e., $\lambda>\lambda^{*}$ ), the second-period equilibrium in the absence of information sharing is in mixed strategies, with banks making poaching offers to their rival's customers with positive probability and some borrowers switching banks. In this case, information sharing eliminates the financing of unproductive projects and reduces the switching costs incurred by talented entrepreneurs. Since the amount of these gains may or may not outweigh the increase in banks' profits, information sharing may or may not hurt talented entrepreneurs.

Acknowledgments We thank two anonymous referees and the coeditor María Ángeles de Frutos for very valuable comments. Financial support from the Spanish Ministry of Education and Science, SEJ200767895-CO4-02 and ECO2010-21393-C04-01, is gratefully acknowledged.

Open Access This article is distributed under the terms of the Creative Commons Attribution License which permits any use, distribution, and reproduction in any medium, provided the original author(s) and the source are credited.

\section{Appendix}

\section{Proof of Proposition 3.1}

(a) Given that bank $j$ does not offer any poaching rate to bank $i$ 's previous customers, bank $i$ 's best response is to set $R_{2}^{i}=v$. Conversely, given that bank $j$ offers a rate $R_{2}^{j}=v$ to its own previous customers, bank $i$ obtains poaching profits by offering these customers the poaching rate $Q_{2}^{i}$. These profits are:

$$
\begin{aligned}
& P_{2}^{i}\left(Q_{2}^{i}, v\right)=\left(1-\mu_{i}\right)\left\{\lambda\left(\pi Q_{2}^{i}-R_{0}\right)-(1-\lambda) R_{0}\right\} \quad \text { if } Q_{2}^{i} \leq v-\bar{b} / \pi \\
& \left(1-\mu_{i}\right)\left\{\lambda \pi\left(\pi Q_{2}^{i}-R_{0}\right)\left(v-Q_{2}^{i}\right) / \bar{b}-(1-\lambda) R_{0}\right\} \text { if } v-\bar{b} / \pi \leq Q_{2}^{i} \leq v
\end{aligned}
$$

Maximization of $P_{2}^{i}\left(Q_{2}^{i}, v\right)$ with respect to $Q_{2}^{i}$ leads to:

$$
\begin{array}{cl}
Q_{2}^{i}=\left(R_{0}+\pi v\right) / 2 \pi & \text { if } \pi v-R_{0} \leq 2 \bar{b} \\
v-\bar{b} / \pi & \text { if } 2 \bar{b} \leq \pi v-R_{0} .
\end{array}
$$

Thus, under the assumption that $(9 / 8)\left(\pi v-R_{0}\right) \leq 2 \bar{b}$, bank $i$ 's best response leads to poaching profits equal to

$$
\begin{aligned}
& P_{2}^{i}\left(\left(R_{0}+\pi v\right) / 2 \pi, v\right)=\left(1-\mu_{i}\right)\left\{\lambda\left(\pi v-R_{0}\right)^{2} / 4 \bar{b}-(1-\lambda) R_{0}\right\} \leq 0 \\
& \quad \text { if and only if } \lambda \leq \lambda^{*} .
\end{aligned}
$$

Thus, when $\lambda<\lambda^{*}$, bank $i$ 's best response to $R_{2}^{j}=v$ is not to offer any poaching rate. 
(b) Consider now the case $\lambda>\lambda^{*}$. Clearly, it is not an equilibrium that bank $i$ (i=A, B) sets $R_{2}^{i}=v$ and refrains from offering any poaching rate $Q_{2}^{i}$ because, given that the rival bank $j$ sets $R_{2}^{j}=v$, bank $i$ can obtain strictly positive poaching profits.

Consider instead an equilibrium (in mixed strategies) in which bank $i$ offers a rate $R_{2}^{i}$ to its previous customers and makes a poaching offer $Q_{2}^{i}$ to bank $j$ 's customers with probability $\alpha$ and refrains from making any offer to them with probability $(1-\alpha)$.

Given $R_{2}^{j}$, the poaching profits that bank $i$ obtains with the offer $Q_{2}^{i}$ are:

$$
\begin{aligned}
& P_{2}^{i}\left(Q_{2}^{i}, R_{2}^{j}\right)=\left(1-\mu_{i}\right)\left\{\lambda\left(\pi Q_{2}^{i}-R_{0}\right)-(1-\lambda) R_{0}\right\} \quad \text { if } Q_{2}^{i} \leq R_{2}^{j}-\bar{b} / \pi \\
& \left(1-\mu_{i}\right)\left\{\lambda \pi\left(\pi Q_{2}^{i}-R_{0}\right)\left(R_{2}^{j}-Q_{2}^{i}\right) / \bar{b}-(1-\lambda) R_{0}\right\} \text { if } R_{2}^{j}-\bar{b} / \pi \leq Q_{2}^{i} \leq R_{2}^{j} \\
& \left(1-\mu_{i}\right)\left\{-(1-\lambda) R_{0}\right\} \quad \text { if } R_{2}^{j} \leq Q_{2}^{i} \text {. }
\end{aligned}
$$

On the other hand, given that bank $i$ sets a poaching rate $Q_{2}^{i}$ with probability $\alpha$ and does not poach with probability $(1-\alpha)$, the profits that bank $j$ obtains on its own customers are:

$$
\begin{aligned}
& I_{2}^{j}\left(R_{2}^{j}, Q_{2}^{i}, \alpha\right)=\mu_{j}\left\{\alpha\left[\lambda\left(\pi R_{2}^{j}-R_{0}\right)\left(\bar{b}-\pi\left(R_{2}^{j}-Q_{2}^{j}\right)\right) / \bar{b}\right]\right. \\
&\left.+(1-\alpha)\left[\lambda\left(\pi R_{2}^{j}-R_{0}\right)\right]\right\} \quad \text { if } Q_{2}^{i} \leq R_{2}^{j} \leq Q_{2}^{i}+\bar{b} / \pi \\
& \mu_{j}\left\{(1-\alpha)\left[\lambda\left(\pi R_{2}^{j}-R_{0}\right)\right]\right\} \text { if } Q_{2}^{i}+\bar{b} / \pi \leq R_{2}^{j} \leq v
\end{aligned}
$$

In equilibrium it is not possible to have $Q_{2}^{i} \leq R_{2}^{j}-\bar{b} / \pi$, for these rates imply that, unless $R_{2}^{j}=v$, bank $j$ can increase the profits $I_{2}^{j}\left(R_{2}^{j}, Q_{2}^{i}, \alpha\right)$ by increasing $R_{2}^{j}$. But if $R_{2}^{j}=v$, then bank $i$ can obtain strictly positive poaching profits and therefore, it will never refrain from making a poaching offer. Also, $R_{2}^{j} \leq Q_{2}^{i}$ is not possible either because the poaching profits become strictly negative and bank $i$ will not make any poaching offer at all.

Suppose then that, in equilibrium, $R_{2}^{j}-\bar{b} / \pi \leq Q_{2}^{i} \leq R_{2}^{j}$. Given $R_{2}^{j}$, the optimal response $Q_{2}^{i}$ will indeed lie in this segment if and only if $0 \leq \pi R_{2}^{j}-R_{0} \leq 2 \bar{b}$. In such a case, the poaching profits, $P_{2}^{i}\left(Q_{2}^{i}, R_{2}^{j}\right)$, will reach a maximum of $P_{2}^{i}=$ $\lambda\left(\pi R_{2}^{j}-R_{0}\right)^{2} / 4 \bar{b}-(1-\lambda) R_{0}$ when $Q_{2}^{i}=\left(R_{0}+\pi R_{2}^{j}\right) / 2 \pi$. For bank $i$ to be indifferent between offering this rate and not making any offer, these profits must be equal to zero, which implies $R_{2}^{j}=\left[R_{0}+\left(4 \bar{b}(1-\lambda) R_{0} / \lambda\right)^{1 / 2}\right] / \pi$ and, therefore, $Q_{2}^{i}=\left[R_{0}+\left(\bar{b}(1-\lambda) R_{0} / \lambda\right)^{1 / 2}\right] / \pi$. It is easy to check that given this value of $R_{2}^{j}$, $0 \leq \pi R_{2}^{j}-R_{0} \leq 2 \bar{b}$ is indeed satisfied when $\lambda>\lambda^{*}$.

Consider now the optimality of bank $j$ 's offer, $R_{2}^{j}$. The function $I_{2}^{j}\left(R_{2}^{j}, Q_{2}^{i}, \alpha\right)$ is non-concave in $R_{2}^{j}$. In the segment $Q_{2}^{i}+\bar{b} / \pi \leq R_{2}^{j} \leq v$, it reaches a maximum at $R_{2}^{j}=v$, whereas in the segment $Q_{2}^{i} \leq R_{2}^{j} \leq Q_{2}^{i}+\bar{b} / \pi$, it does so when $\alpha\left[-2 \pi R_{2}^{j}+R_{0}+\bar{b}+\pi Q_{2}^{i}\right] / \bar{b}+(1-\alpha)=0$. 
By replacing $R_{2}^{j}=\left[R_{0}+\left(4 \bar{b}(1-\lambda) R_{0} / \lambda\right)^{1 / 2}\right] / \pi$ and $Q_{2}^{i}=\left[R_{0}+(\bar{b}(1-\right.$ ג) $\left.\left.R_{0} / \lambda\right)^{1 / 2}\right] / \pi$ in this condition, we obtain $\alpha=\left[\bar{b} \lambda / 9(1-\lambda) R_{0}\right]^{1 / 2}$. Therefore, it is necessary that $\alpha, R_{2}^{j}$, and $Q_{2}^{i}$ take precisely these values to have a mixed equilibrium as stated above. On the other hand, given that $\alpha$ and $Q_{2}^{i}$ take these values, a comparison of the two local maxima of the function $I_{2}^{j}\left(R_{2}^{j}, Q_{2}^{i}, \alpha\right)$ shows that the global maxima is indeed interior if and only if $\alpha(1-\alpha)\left(\pi v-R_{0}\right) \leq 4 \bar{b} / 9$, which holds under the condition $(9 / 8)\left(\pi v-R_{0}\right) \leq 2 \bar{b}$.

\section{Proof of Proposition 3.2}

(a) Consider first the case $\lambda<\lambda^{*}$. It is an equilibrium that both banks charge the interest rate $R_{1}^{*}=\left[R_{0}-\delta \lambda\left(\pi v-R_{0}\right)\right] / \lambda \pi$ : by replacing $R_{1}^{i}$ with $R_{1}^{*}$ in (4) and using $G_{2}^{i}=\mu_{i} \lambda\left(\pi v-R_{0}\right)$, we see that this rate leads to bank $i$ 's overall profits $G^{i}=0$. Given bank $j$ 's choice of $R_{1}^{*}$, if bank $i$ charges an interest rate above $R_{1}^{*}$, it will attract no consumers and, therefore, it will earn zero profits. If, on the other hand, bank $i$ charges an interest rate below $R_{1}^{*}$, it will attract all consumers. By replacing such a value in (4) we obtain that overall profits are negative. Thus, no bank can increase its profits by unilaterally charging a different interest rate. We now show that there is no other equilibrium. Suppose first that banks charge different interest rates, $R_{1}^{*} \leq R_{1}^{j}<R_{1}^{i}$. Since bank $j$ can raise its interest rate and still attract all consumers — as long as it keeps the rate below $R_{1}^{i}$-and thus earn higher profits, this cannot be an equilibrium. Suppose instead that banks charge the same interest rates $R_{1}^{*}<R_{1}^{i}=R_{1}^{j}$. Then bank $i$ will attract a fraction $\mu_{i}$ of the consumers and will earn positive profits on them. If bank $i$ reduces its interest rate in an infinitesimal amount, its profits on these consumers will accordingly be reduced in an infinitesimal amount. On the other hand, it will now attract the remainder $\left(1-\mu_{i}\right)$ consumers and earn positive profits on them. Thus, bank $i$ 's profits will be higher, showing that we do not have an equilibrium. Finally, notice that, since negative profits can be avoided by charging $R_{1}^{*}$, it is not an equilibrium to have a bank charging an interest rate below $R_{1}^{*}$ to attract consumers.

(b) The analysis of the case $\lambda>\lambda^{* *}$ only differs from the previous one in the fact that now $G_{2}^{i}=\mu_{i} \lambda(4 \bar{b} / 9 \alpha)$.

\section{Reference}

Gehrig T, Stenbacka R (2007) Information sharing and lending market competition with switching costs and poaching. Eur Econ Rev 51:77-99 